Research Article

\title{
Application of Mobile App in English Teaching in an Intelligent Environment
}

\author{
Haihua Tu \\ College of Foreign Languages, Shaoxing University, Shaoxing, Zhejiang 312000, China \\ Correspondence should be addressed to Haihua Tu; tuhaihua0628@usx.edu.cn
}

Received 26 March 2021; Revised 28 April 2021; Accepted 13 May 2021; Published 30 May 2021

Academic Editor: Sang-Bing Tsai

Copyright (C) 2021 Haihua Tu. This is an open access article distributed under the Creative Commons Attribution License, which permits unrestricted use, distribution, and reproduction in any medium, provided the original work is properly cited.

\begin{abstract}
With the rapid development of social economy and technology, the application of technology in the field of education has also been further developed. The past paper information carriers can no longer fully meet the development needs of the modern society. In this context, this thesis explores a learning model that combines mobile learning based on mobile apps with English teaching. The school's hardware facilities have been continuously updated with the development of social information technology, and intelligent voice systems have been continuously introduced into classrooms. This article focuses on exploring the application of mobile app in English teaching in a smart environment, using the implementation of the mobile learning English model, and dividing two identical classes into an experimental class and control class through questionnaires and comparisons. The experimental design finally concluded that the use of mobile app to assist English teaching in all aspects of the relative improvement of the English performance of the class, the teaching effect is obvious, effectively improves students' interest in learning English and, at the same time, realizes students' mobile learning, changes the scope of teaching activities from classroom changes to a wider range, and plays a role in consolidating and supplementing classroom English.
\end{abstract}

\section{Introduction}

1.1. Background and Significance. At present, China's English teaching is still based on the traditional classroom teaching, using the traditional face-to-face teaching method $[1,2]$. With the continuous development of multimedia technology, many colleges and universities have introduced multimedia computer, audio-visual technology, electronic whiteboard, and so on, in order to better carry out English teaching. However, it cannot get rid of the shortcomings of traditional classes.

1.2. Foreign Research. Mobile learning first started in the United States and developed relatively early and matured abroad. It pays more attention to research and can collect more evidence and application examples. At first, Carnegie Mellon University started a research project called Wire Andrew [3], and then, teachers and students on the campus experienced the convenience of wireless learning supported by wireless technology in this research project. Especially in the context of the rapid development of wireless communication technology, mobile learning has developed rapidly, making mobile learning applicable to all areas of life. These include education, especially basic education, higher education, and lifelong learning. The European research project "Next-Generation Mobile Learning" based on vocational training aims to promote work-based learning and solve practical problems. The mobile learning courses of the Human-Computer Interaction Laboratory at the University of California, Berkeley, are suitable for elementary and secondary education. The research content is to improve the effectiveness of classroom communication between teachers and students and the influence of external learning, which shows that foreign research on mobile learning is based on experience and application-based research $[4,5]$.

1.3. Domestic Research. The research and practice of mobile learning in my country began at the beginning of the 21 st century and at the later stage, mainly under the auspices of the Ministry of Education. In recent years, with the 
development of China's comprehensive strength, especially its economic strength, investment in mobile learning has increased relatively, conditions in all aspects have increased, and the scale has also increased [6].

Most of the literature is a more general description of how information technology and all English disciplines are integrated. In this part of the research, the most extensive research is the application of information technology in English teaching and vocabulary teaching, while the oral and written parts of English are relatively weak [7, 8].

\subsection{Innovation.}

(1) This article mainly uses questionnaire surveys and interviews to investigate and analyze the current students' English learning needs and learning habits in preparation for applied research.

(2) This article analyzes the application effect of app in English extracurricular learning. Through performance comparison, questionnaire surveys, field interviews, and other methods, the final learning effect of the experimental class and the control class is analyzed].

1.5. Structure of the Article. This paper mainly studies the application of mobile app in English Teaching in an intelligent environment:

The first chapter introduces the background and innovation of this paper. The second chapter introduces the development of mobile app and the application of sensors in English Teaching in an intelligent environment. The third chapter conducts an English teaching experiment in an intelligent environment. The fourth chapter discusses the experimental results. The fifth chapter summarizes the content of this paper.

\section{Research Methods}

2.1. Smart Environment. With the introduction of nonuniversal computing, this idea gradually emerged. According to Mark Weiser's definition, a smart environment is a real scene composed of interactive sensors, arithmetic units, monitors, and computing units, which connects daily objects in our lives through the network. Also, it provides users with various intelligent services [9]. The intelligent environment brings together many computing fields, such as pervasive computing, intelligent systems and environment perception, and object interaction. The key to environmental intelligence is to realize the effective monitoring of the environment by users, as shown in Figure 1.

The sensor node is the basic unit of the communication network in the intelligent environment. It is a physical unit integrated by a power supply unit, a microprocessor unit, a sensor unit, and a communication unit. For different applications, modules such as installation, power integration, and drivers can be added. The function of the intelligent environment is mainly to manually develop the sensor nodes in the scene. The nodes work together to perceive and collect

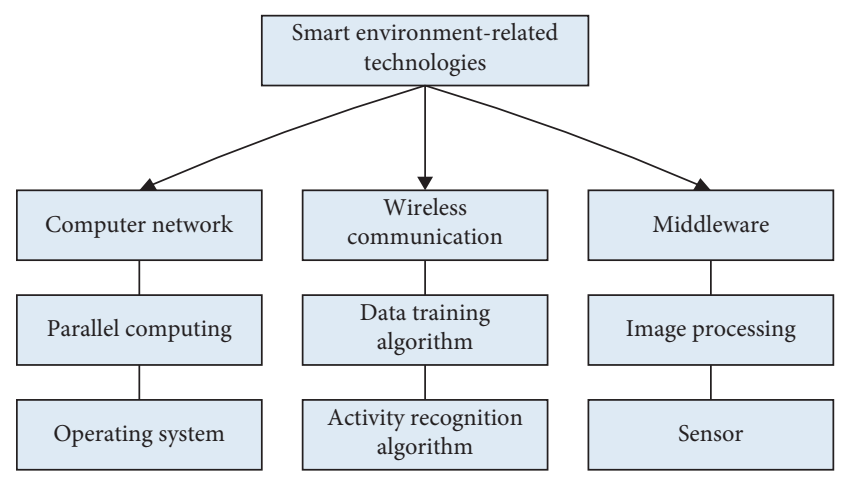

FIGURE 1: Smart environment-related technologies.

environmental state information or monitor the object information in the scene and use single or multihop relays through single or two sensors. Communication between nodes is used to convey information. The collection node analyzes the received data and finally sends the analysis and processing results to computers, mobile phones, and other user terminals through the Internet, satellites, mobile networks, etc., for effective monitoring and processing $[10,11]$.

2.2. Mobile App. App is the abbreviation of the word application and refers to third-party applications that can be used on mobile smart terminals. According to the product format of the network and the new multimedia application system, applications can be mainly divided into local applications, page applications, and hybrid applications. It can not only provide users with various entertainment services, such as local services, online shopping, and games but also provide many educational service functions, such as interaction, learning, and sharing [12].

Intelligent mobile terminals have quietly and profoundly affected people's way of life and changed people's way of learning. Among them, smartphones have the most profound and extensive impact on human beings. Smart mobile terminal is user centered and is developing in the direction of more intelligent and environmental protection, involving more and more fields. Mobile intelligent terminal can enable students to carry out mobile learning and expand the scope of teaching activities to a broader field. Students can start learning activities anytime and anywhere according to their own needs, can make full use of all kinds of free time to learn, can improve students' interest in learning, and can use a variety of teaching resources to learn and carry out teachingrelated activities $[13,14]$. In terms of technical operation and implementation, these mobile terminals include multimedia functions, such as audio and video, and are smart tools that support data transmission and information processing capabilities.

Private information is a kind of personal information that has nothing to do with the interests of the group and users do not want others to know. Privacy leakage is to illegally obtain or disclose the user's private information without the user's permission [15]. In the past, mobile phones were people's only communication tools, which only stored personal information such as address books or short 
messages, and people performed more network activities on PCs. Now, with the rapid development of the mobile Internet, mobile devices represented by mobile phones and tablets are playing an increasingly important role in people's lives. Mobile phones no longer only have the functions of making calls and sending text messages, but have more and more the same functions as PCs, and they also have advantages that PCs cannot match. People are relying more and more on mobile phones for office work and entertainment, so more and more private information is stored in mobile phones [16, 17].

According to the time that students use the app and use different learning tasks to learn, so as to judge the basic process of classroom activities and then infer the percentage of available time from the teacher's guidance and students' autonomous learning using the mobile app, the basic analysis steps are as follows:

$$
\begin{array}{r}
\phi_{\text {classroom }}=T_{\text {Face-to-face }}: T_{\text {learn }}, \\
T_{\text {learn }}=T_{\text {practice }}+T_{\text {Interactive }}, \\
T_{\text {Face-to-face }} 40-T_{\text {learn }} .
\end{array}
$$

The formula for calculating the proportion of class time allocation is

$$
\phi_{\text {classroom }}=\frac{40-T_{\text {practice }}-T_{\text {Interactive }}}{T_{\text {practice }}+T_{\text {Interactive }}} .
$$

Through the corresponding analysis of the learning data, the result of evaluating the learning effect of the students is obtained, the timeliness and reliability of learning are improved, and the teachers are helped to understand the learning situation of the students in time and teach students in accordance with their abilities.

2.3. Mobile Learning. Mobile learning is a teaching concept produced with the progress and development of science and technology, which can be summarized as a form of combining technology and learning. Mobile learning requires the support of related technologies and equipment. It refers to the learning behavior of students through mobile devices. This behavior can greatly expand the scope of learning and change the limitations of traditional teaching. Students can use mobile devices for learning activities anytime anywhere. Focusing on technology can achieve fast learning. Usually, it uses mobile terminals (smartphones, tablets, etc.) to learn anytime and anywhere. Through these mobile devices, the purpose of learning and providing learning resources can be achieved. Portable learning can be simply summarized as a new type of learning model, which takes technology as the center and means, takes knowledge and learning as the main goal, and combines technology and learning. Usually, it uses portable terminal devices (mobile phones, tablets, learning machines, etc.) to learn anytime and anywhere. The role of these mobile terminals is to help learning and provide learning resources [18].

Mobile learning is guided by the theory of lifelong learning. Students can use portable terminal devices (including laptops) to study anytime and anywhere according to their needs. It can assist students by connecting mobile devices to the Internet for learning or downloading online resources in mobile learning devices. Mobile learning can be used as a supplement to traditional teaching methods. Mobile learning has been accepted by students and aroused people's interest. Traditional classroom teaching is difficult to cultivate the personality of each student. Students can choose their own portable learning resources for mobile learning according to their learning needs, so as to achieve personalized learning. It is very useful for students to check omissions and make up for their shortcomings in time $[19,20]$.

At present, the main carrier of mobile learning is smart mobile terminals. Mobile smart terminals can access the Internet and receive resources such as text, images, and videos through the Internet. At the same time, the terminal can communicate with others anytime and anywhere. The development of technology has made mobile smart terminals more and more popular. Most students already have smart devices such as smartphones, tablets, and e-books. The advanced development of network technology makes it easier for mobile smart terminals to access the Internet, and mobile learning has become a reality at the technical level.

\subsection{The Application of Sensors in English Teaching in the Smart} Environment. This article provides a sensor teaching demonstration system [21], including a sensor screen window and desk. This auxiliary model allows trainers to learn sensor technology and experience sensor products through physical displays and multimedia demonstrations of various sensors and lays the foundation for basic sensor applications. It can be used in the technical field of English teaching equipment, especially related to English teaching systems with human infrared sensors [22, 23]. Including the teaching desk, the teaching desk is equipped with a computer, the computer is connected with the audio equipment, the computer is connected with the spoken language trainer set on the desk through the wireless transmission module, and the desk is also equipped with an information recognition device, which is connected to the spoken language trainer. The spoken language trainer includes a shell. The shell is equipped with a recorder. The recorder is connected with a processor set in the shell. The processor is connected to a memory for storing students' personal information and English learning materials. Connection: the information identification device includes a fingerprint collector, which is connected to the processor. The teaching table is also equipped with a human body infrared sensor, which is connected to the computer, which can help students in oral education and help teachers draw lines and promote energy saving, as shown in Figures 2 and 3.

\subsection{Feasibility Analysis of Using Smart Mobile Terminals to Learn English outside Class.}

(1) Students can use the voice function to interact with teachers or real-time learning partners or use real- 


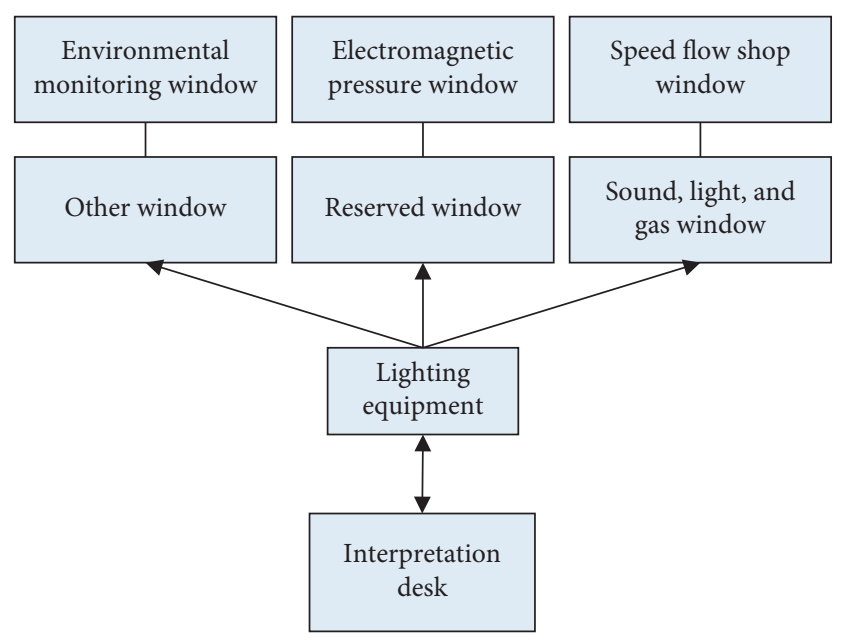

Figure 2: Sensor display system.

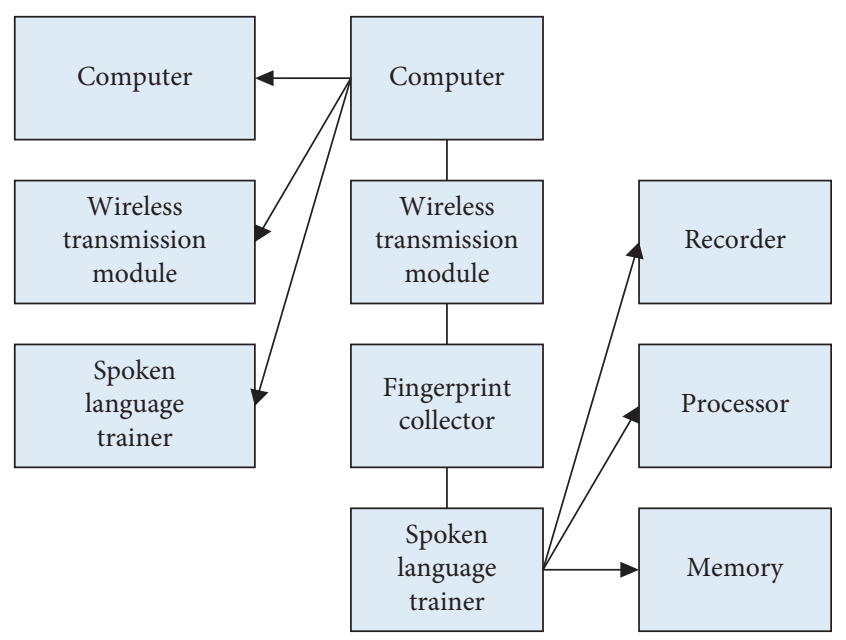

FIGURE 3: English teaching system of the human infrared sensor.

time placement software. It has good multimedia processing functions, powerful information processing functions, a complete audio and video playback system, and camera functions equivalent to a camera.

(2) We can already use mobile smart terminals to realize many previous ideas. From a technical point of view, mobile learning is no longer difficult. With the support of existing technologies, students can use mobile smart terminals to learn what they want to master anytime and anywhere, and teachers can also use these technologies to conduct teaching activities anytime and anywhere $[24,25]$.

\section{Experiment}

In order to stimulate students' interest in learning English, smart mobile apps are introduced into English classroom teaching, and the following hypothesis is put forward: The introduction of mobile apps in English classroom teaching can stimulate students' interest in learning and improve teaching effects. The connectivity of smartphones and tablets is very strong. Also, the real-time interactivity is also very powerful. Learners can use the voice function to interact with teachers or learning partners in real time, and they can also use software for real-time positioning, which can be considered quite convenient in information communication and exchange.

3.1. Research Objects. In the business English major of the school, two classes composed of 61 students and taught by the same English teacher were selected as the experimental class and the control class. In the experimental classroom, mobile apps are used to assist English teaching, while in the control classroom, traditional teaching methods are used. After selecting the experimental class, the student's smartphone ownership and the status of the mobile network connection are looked upon.

\subsection{Experimental Method}

(1) Observation method: during the experiment teaching process, the performance of the classroom and students' participation in the experiment classroom and control classroom are observed.

(2) Experimental method: in the experimental classroom, teachers use mobile apps to assist English teaching in the teaching process. In the control classroom, teachers use traditional teaching functions and students are not allowed to use mobile phones.

(3) Test method: pre-experiment tests are conducted in the experimental class and the control class to understand the level of students. After a semester of experiments, postexperiment tests are performed to obtain results, they are compared with the data before the experiment.

3.3. Experimental Results. The students in the experimental class and the control class were not interested in English before the test. The proportion of students interested in English in the experimental class was $38.76 \%$, while the proportion of students interested in English in the control class was $35.91 \%$. The comparison found that the pre-experiment score test difference between the two classes of students is not obvious and their English proficiency is basically the same, as shown in Table 1 .

Through the analysis of the experimental data, it is concluded that the class participates in the smartphone appassisted teaching experiment. The average score increased by 12 points, the number of failures decreased to single digits, and the number of high scores increased to 13. The students' academic performance has improved. It reduces the opportunities for students to play games and can increase students' interest in learning and classroom participation. Mobile app is especially suitable for English learning. Smartphone app is used to help teach English. It can improve teaching effects and stimulate students' interest in learning. 
TABle 1: Comparison before testing.

\begin{tabular}{lcccccc}
\hline Class & Interested (\%) & Not interested (\%) & $<60$ & $60-80$ & $80-100$ & Average score \\
\hline Experimental class & 38.76 & 61.34 & 19 & 36 & 6 & 57.2 \\
Control class & 35.91 & 64.09 & 20 & 34 & 7 & 54.9 \\
\hline
\end{tabular}

\section{Analysis of Mobile App Usage}

4.1. Smart Electronic Device Learning. The age of students is generally 13-22 years. The learning of knowledge is becoming more and more specific, the relationship with life is getting closer, and the cognition and understanding of knowledge is getting deeper and more thorough. Therefore, we should firmly grasp this characteristic of students in learning English and provide students with as many useful things as possible. In this way, students' oral expression skills can be improved. This article selects 100 students from a certain school and investigates the more inclined English learning methods. $37 \%$ of learners hope to learn English in a real language environment, but are restricted by conditions. $45 \%$ of students tend to use mobile apps to learn while using modern technology to learn English. The form is more colorful and more in line with the characteristics of student learning, as shown in Figure 4.

4.2. Purpose of Using the Purchased Smartphone or Tablet. Most students buy smartphones or tablets mainly to communicate with others. Indeed, the initial function of mobile phones is to communicate with others. In the survey, $52 \%$ of learners bought smartphones or tablets because of their learning needs. For computers, it means that, among students, there are still learners who have the awareness of using mobile terminals such as smartphones to learn. However, from the second question, from the perspective of the use of mobile devices such as smartphones by learners, those who study online only occupy $21 \%$, while $44 \%$ used to play games, indicating that learners in school are not aware of using smartphones or tablets for learning and are more obsessed with using smartphones for online games. It can be seen that if teachers and researchers do not control learners' use of smartphones and tablets in time, lower-grade students are likely to go astray, which will not only delay their studies but also endanger their physical and mental health. We can correctly guide to use smartphones and tablet computers as carriers and use mobile apps to develop a reasonable and effective learning model for them to improve learning efficiency, as shown in Figure 5.

\subsection{Learning Initiative in Experimental and Controlled} Classes. In order to better implement the teaching application and understand the current situation of students' English learning, this paper conducts a questionnaire survey on 61 students in the class for one semester and then conducts a questionnaire survey on English teaching based on an intelligent environment after one semester. We designed, distributed, and collected 61 questionnaires. The statistical results are as follows: from the data, it can be seen that, before the implementation of mobile teaching, the

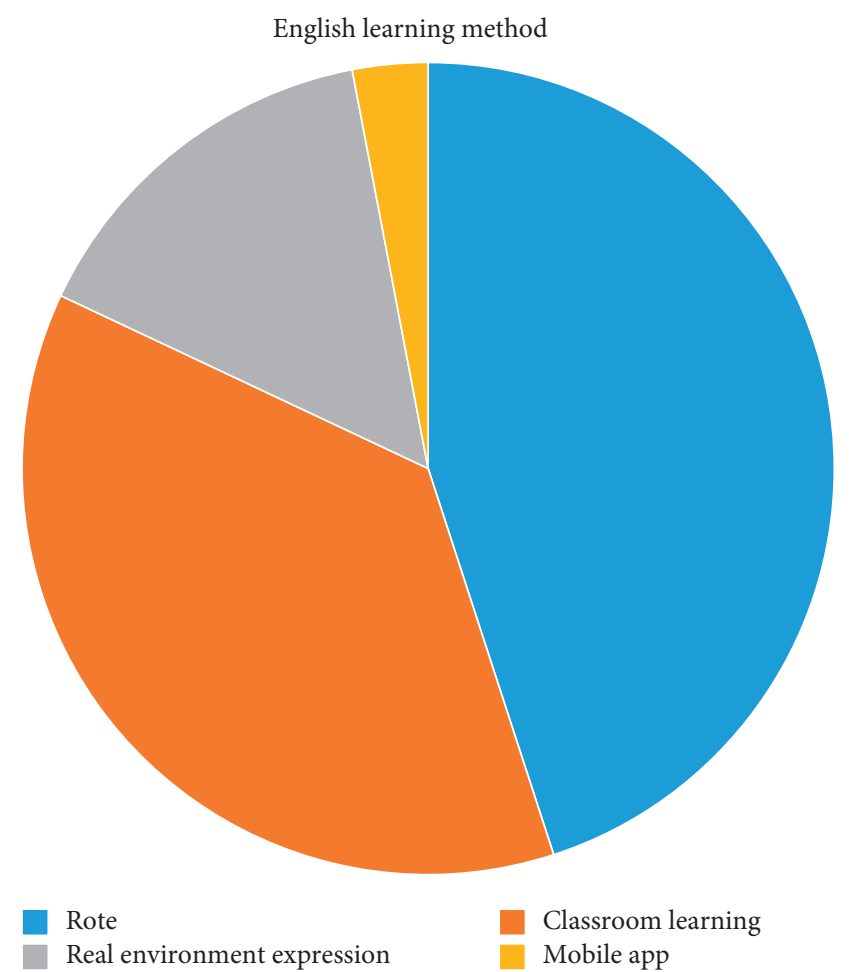

FIgUre 4: A questionnaire about students' preference for English learning styles.

proportion of students who often take the initiative to speak accounted for only $24 \%$, which increased to $76 \%$ after a semester. This reflects that students do not speak even in class, and they speak passively because of the teacher's questions. At most, $21 \%$ of students who dare not speak in English usually speak English, followed by $26 \%$ of students who cannot pronounce correctly and $19 \%$ of students who are restricted by the number of words. It seems that students who use English for dialogue and communication are English. As the biggest difficulties encountered in learning, these problems have been greatly improved after the implementation of mobile teaching. More students like English and use correct methods to improve English learning, as shown in Figure 6.

4.4. Use of Mobile App. In order to evaluate the learning effect of students' self-learning during the semester, the smart app backstage collects data on students' self-learning using the smart app during the semester, including practice data, topic details, etc. The built-in activities of the smart app fall into three categories: one is vocabulary practice, the other is text practice, and the third is listening practice. The activities of word practice include "vocabulary practice"; the activities of text practice include "text memorization," 


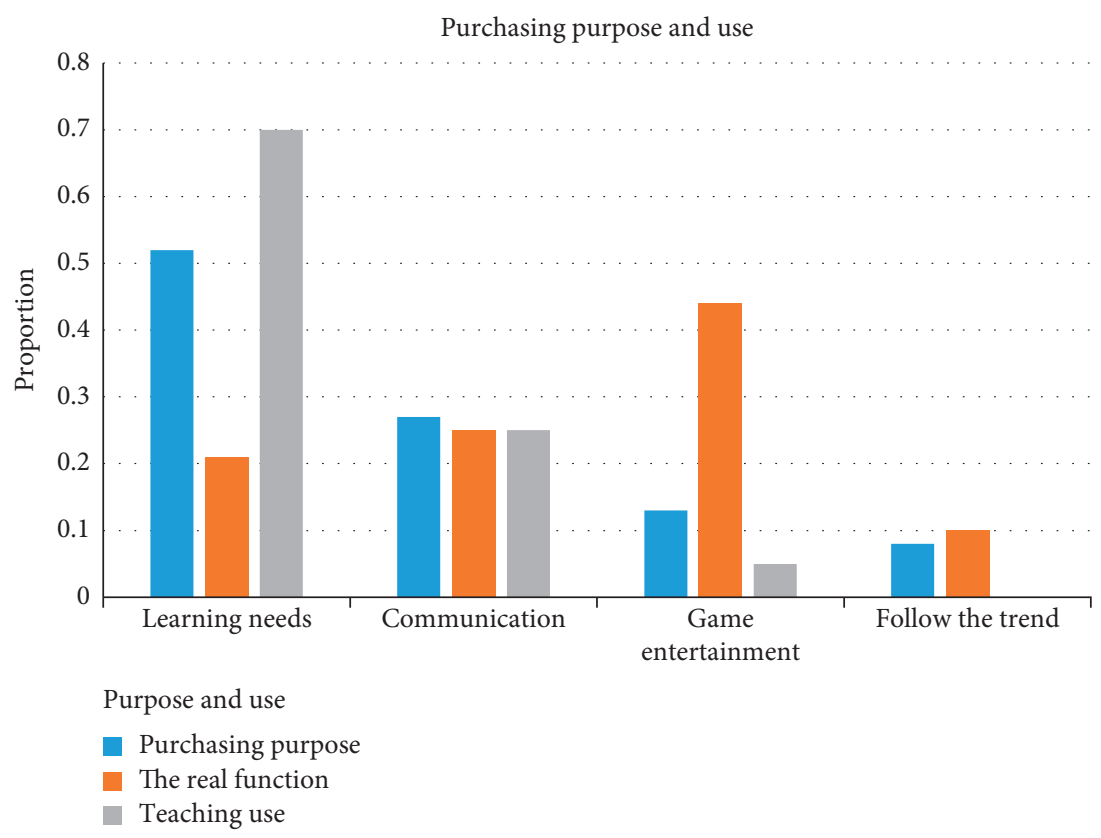

FIGURE 5: Purchasing purpose and use of smart products.

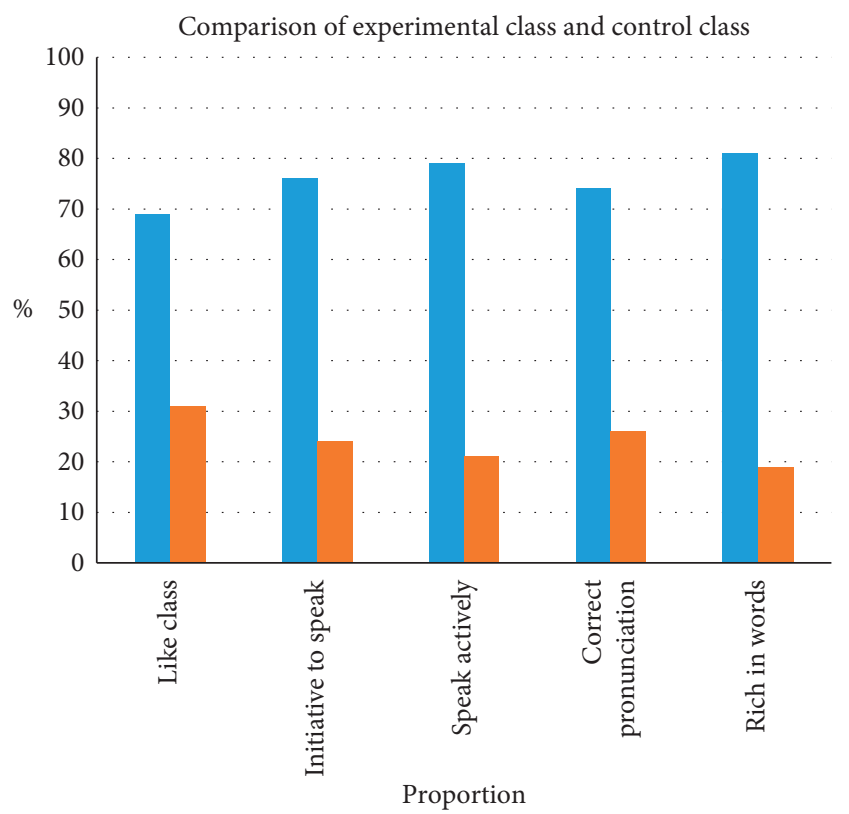

- Experimental class

- Control class

Figure 6: Comparison of the experimental class and control class.

"knowledge practice," and "application practice"; the activities of listening practice include "listening sequence." The following figure shows the comparison of the average correct rate of each activity performed by the smart app in the 6 experimental classes in this semester, as shown in Figure 7 .

4.5. Mobile App Learning Resources. According to the understanding that students have their own mobile phones, they have the necessary conditions for mobile learning based on smartphones. One is to be familiar with the software used in this activity, what are the functions of the software, and how to use the software for learning which requires learners to master in advance. After proficient use of the software, the learning efficiency will not be affected by the software itself. The second is to understand the related matters of this learning activity and be familiar with the activity process. English songs are the best way to easily learn English and cultivate a sense of language. At the same time, 1-2 learners are found every day to upload the English songs they sing to the Q0 group. Everyone will supervise each other and enhance their feelings; when you encounter technical or English learning problems, you can ask questions on QQ at any time, or if you have any good suggestions, you can speak at any time. At the same time, I will contact teachers with rich English majors to help learners solve their difficulties; during these ten days of mobile learning activities, this article will use the voting function in QQ to hold voting activities in the later stage to increase the interest of learning evaluation, as shown in Table 2.

4.6. Mobile App Application in Smart Environment. After the completion of this thesis, English majors can give full play to the advantages of mobile learning, improve learning efficiency and effectiveness, meet the learning needs of students at different levels, truly realize differentiated teaching, and make up for the traditional classroom problems that cannot be realized too much: for example, the concentrated discussion and communication between students and the concentrated answering of questions from teachers to students enable students to truly turn their smartphones into learning tools and truly realize anytime anywhere and diversify mobile learning. 


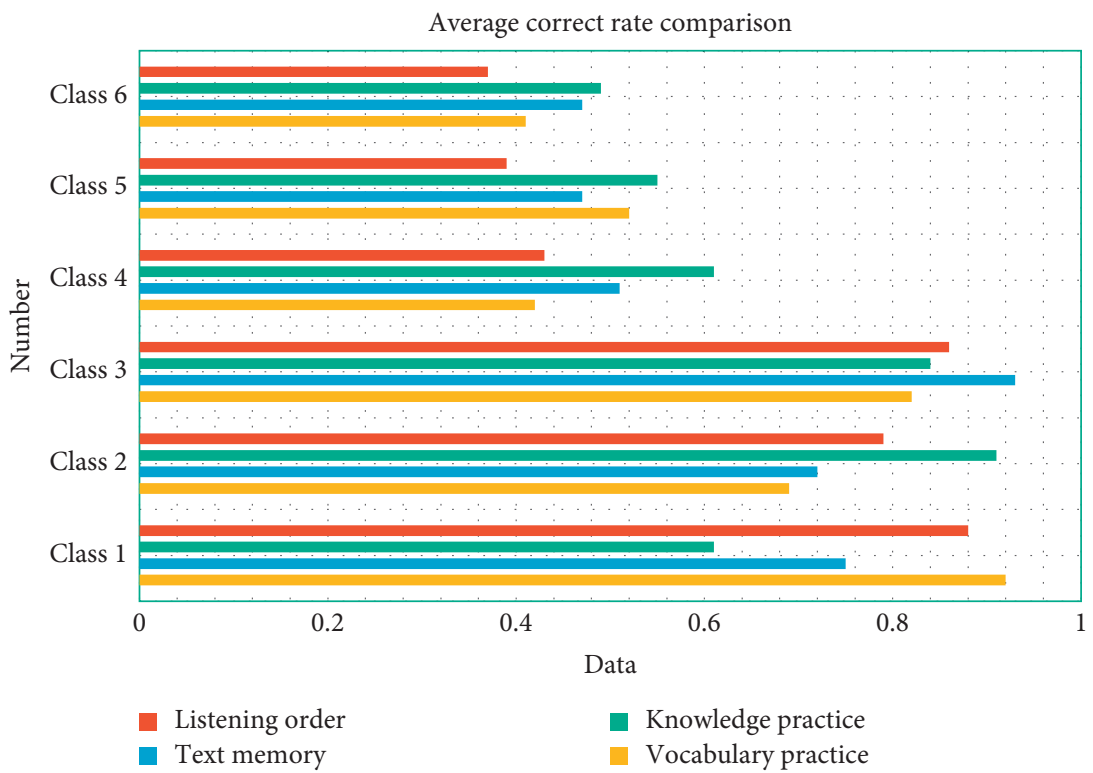

Figure 7: Comparison of the average correct rate of each activity in the experimental class using app.

TABLE 2: Mobile learning and utilization of mobile apps.

\begin{tabular}{lcc}
\hline Time & Content & Mobile app \\
\hline 06:00 & New concept text & Hujiang Net \\
08:00 & Word & Hundred Words \\
09:00 & Exam questions & Hujiang Net \\
14:00 & Proverbs and short stories & Fluent app \\
$20: 00$ & Song & Song Taste \\
$21: 00$ & Ask a day & 10 students \\
\hline
\end{tabular}

(1) The value orientation of mobile learning is established, and students are guided to face the pros and cons of smartphone learning. As a product based on the development of Internet technology, smartphones have the advantages of rich functions and convenient operation. They can meet different needs in English teaching and learning. However, everything has two sides. The emergence of smartphones has brought convenience and great adverse effects. In the network environment, in addition to providing learning functions for students, smartphones also provide a variety of entertainment functions, such as chat and games, causing students to be easily distracted when studying. At the same time, in the process of using smartphones for a long time, students are prone to a sense of dependence on mobile phones, which not only causes students to suffer from insomnia, dizziness, and other conditions but also damages students' enthusiasm for learning. Therefore, in view of the adverse effects of smartphones, it is necessary to clarify its role in English teaching, establish the correct value orientation, let students fully realize the possible shortcomings of mobile learning, and guide students to use smartphones for English learning goals and necessity.

(2) Mobile learning resources are enriched, and smartphone application technology is introduced in teaching. With the development of technology, smartphones are no longer simply communication tools, but more of a comprehensive mobile device that integrates multiple functions, such as voice calls, online chats, entertainment games, and interactive learning. At the same time, with the rapid development of network information technology, the smart functions of smartphones can be realized to the greatest extent. Different students have different learning requirements, and the English ability of different students varies. The unified traditional teaching mode obviously cannot meet the learning needs of students. In order to fully meet the different English learning needs of students, it is necessary to establish a personalized information database for different English modules, combine it with a personalized curriculum resource database, share resources through the network, and promote students to conduct mobile learning under the connection of network technology.

(3) A diversified mobile learning model is built, and the convenience of the smartphone platform is made use of. English is an important communication tool. Under the current English teaching model, the learning effect of students is not very satisfactory. Due to the limitation of teaching location and time, students' learning initiative cannot be fully exerted. In order to break through this limitation and reform the status of English teaching, the school's academic affairs department should establish a diversified mobile learning model, make full use of various learning resources, and give full play to the advantages of smartphones in the context of the popularization of smartphones.

(4) You can use smartphones or tablets to communicate with classmates and teachers, ask each other some 
questions about English learning, or practice oral conversation, which can help those introverted learners actively participate. Finally, learners can use mobile terminals such as smartphones to play some meaningful, easy-to-understand audio books suitable for their English before going to bed, so that they can practice listening and fall asleep with English stories and get a better rest.

\section{Conclusions}

In the context of the continuous development and improvement of information technology and the tremendous development of network communications, mobile learning using emerging technologies has a lot of room for development. In the future, mobile learning will pay more attention to human-computer interaction and learning intelligence. With the introduction of "Internet + education," this thinking about the Internet has caused great changes in traditional education. Education pays more attention to students' problem-solving abilities and cultivating their own learning abilities. Teachers are no longer just sources of knowledge, and students are no longer just recipients of knowledge.

Intelligent mobile terminals and their applications have brought tremendous changes to mobile learning. Open multimedia learning resources are a powerful supplement to traditional printed books. Differentiated teaching materials also give students many choices and stimulate their enthusiasm for learning; rich and easy-to-use online teaching resources have a great influence on traditional teaching resources. Knowledgeable people are no longer the only teachers, and students can follow and choose what they need to learn flexibly according to their needs and weaknesses. Using smartphone app to assist English teaching can improve learning effects and stimulate students' interest in learning. With the popularity of smartphones and the continuous development of mobile learning applications, smartphone applications have become an important part of our daily lives.

From the perspective of technology, mobile learning in the future, under the background of the integration of various wireless network technologies, relying on the ubiquitous "ubiquitous network," the communication service objects will gradually expand from people to anything, with stronger human-computer interaction and diversified development of wearable electronic devices. At the same time, mobile terminals will develop in the direction of more intelligent, multiscreen, and ubiquitous applications. Mobile learning will provide more abundant mobile learning resources for learners, and technology will support future schools. From the perspective of education development, after the integration of modern technology into traditional education, all aspects of traditional education are changing. The purpose and focus of education will be more focused on the cultivation of learners' learning ability, which is more in line with learners' own characteristics. Learning is no longer static words, but flexible pictures and real situations. Teachers are no longer the imparters of knowledge. It is the tutor and helper of learning, and learners can find and solve problems actively through the guidance of teachers.

\section{Data Availability}

No data were used to support this study.

\section{Conflicts of Interest}

The author declares no conflicts of interest.

\section{Acknowledgments}

This work was supported by the Zhejiang Research Institute of Education Science in 2021: Research on the "Shared Growth" Classroom Development Model of College Students Based on Group Dynamics Theory (2021SB066) and Zhejiang Yuexiu University, Foreign Language and Culture Research Institute: The Relationship between Organizational Culture and College English Teaching (2020WGYYWH07).

\section{References}

[1] M. Tentori, L. Escobedo, and G. Balderas, "A smart environment for children with autism," IEEE Pervasive Computing, vol. 14, no. 2, pp. 42-50, 2015.

[2] G. B. Gebremeskel, C. Yi, C. Wang, and Z. He, "Critical analysis of smart environment sensor data behavior pattern based on sequential data mining techniques," Industrial Management \& Data Systems, vol. 115, no. 6, pp. 1151-1178, 2015.

[3] K.-L. A. Yau, D. Chieng, J. Qadir, and Q. Ni, “Towards enhancement of communication systems, networks and applications for smart environment," Journal of Ambient Intelligence and Humanized Computing, vol. 10, no. 4, pp. 1271-1273, 2019.

[4] O. Starostenko, X. Cortés, J. A. Sánchez, and V. AlarconAquino, "Unobtrusive emotion sensing and interpretation in smart environment," Journal of Ambient Intelligence and Smart Environments, vol. 7, no. 1, pp. 59-83, 2015.

[5] J. Chin, V. Callaghan, and S. B. Allouch, "The internet-ofthings: reflections on the past, present and future from a usercentered and smart environment perspective," Journal of Ambient Intelligence and Smart Environments, vol. 11, no. 1, pp. 45-69, 2019.

[6] V. B. M. F. Koy and O. Rodrigues, "Developing smart environment at tourism spots in Jetisharjo RW. 07, Yogyakarta," ARTEKS: Jurnal Teknik Arsitektur, vol. 4, no. 1, pp. 25-32, 2019.

[7] Z. Belghazi, N. Benamar, A. Addaim, and C. A. Kerrache, "Secure WiFi-direct using key exchange for IoT device-todevice communications in a smart environment," Future Internet, vol. 11, no. 12, pp. 1-15, 2019.

[8] M. Sivarathinabala and S. Abirami, "AGRS: automated gait recognition system in smart environment," Journal of Intelligent \& Fuzzy Systems, vol. 36, no. 3, pp. 2511-2525, 2019.

[9] H. Khalid, E. Shihab, M. Nagappan, and A. E. Hassan, "What do mobile app users complain about?" IEEE Software, vol. 32, no. 3, pp. 70-77, 2015.

[10] S. L. Lim, P. J. Bentley, N. Kanakam, F. Ishikawa, and S. Honiden, "Investigating country differences in mobile app user behavior and challenges for software engineering," IEEE Transactions on Software Engineering, vol. 41, no. 1, pp. 40-64, 2015. 
[11] Y. Fukuoka, C. L. Gay, K. L. Joiner, and E. Vittinghoff, "A novel diabetes prevention intervention using a mobile app," American Journal of Preventive Medicine, vol. 49, no. 2, pp. 223-237, 2015.

[12] J. Dahne, C. Lejuez, J. Kustanowitz et al., "Moodivate: a selfhelp behavioral activation mobile app for utilization in primary care-development and clinical considerations," The International Journal of Psychiatry in Medicine, vol. 52, no. 2, pp. 160-175, 2017.

[13] O. Sert, S. Elik, and E. Baran, "The affordances of mobile-app supported teacher observations for peer feedback," International Journal of Mobile and Blended Learning, vol. 10, no. 2, pp. 36-49, 2018.

[14] Y. Wang and M. S. Christiansen, "An investigation of Chinese older adults' self-directed english learning experience using mobile apps," International Journal of Computer-Assisted Language Learning and Teaching, vol. 9, no. 4, pp. 51-71, 2019.

[15] G. Aceto, D. Ciuonzo, A. Montieri, and A. Pescapé, "Multiclassification approaches for classifying mobile app traffic," Journal of Network and Computer Applications, vol. 103, pp. 131-145, 2018.

[16] V. F. Taylor, R. Spolaor, M. Conti, and I. Martinovic, "AppScanner: automatic fingerprinting of smartphone apps from encrypted network traffic," in Proceedings of the 2016 IEEE European Symposium on Security and Privacy (EuroSe $P$ ), IEEE, Saarbruecken, Germany, March 2016.

[17] G. Aceto, G. Bovenzi, D. Ciuonzo et al., "Characterization and prediction of mobile-app traffic using markov modeling," IEEE Transactions on Network and Service Management, vol. 18, no. 1, pp. 907-925, 2021.

[18] K. F. Hashim, F. B. Tan, and A. Rashid, "Adult learners' intention to adopt mobile learning: a motivational perspective," British Journal of Educational Technology, vol. 46, no. 2, pp. 381-390, 2015.

[19] S. M. Land and H. T. Zimmerman, "Socio-technical dimensions of an outdoor mobile learning environment: a three-phase design-based research investigation," Educational Technology Research and Development, vol. 63, no. 2, pp. 229-255, 2015.

[20] E. Tan and H.-J. So, "Rethinking the impact of activity design on a mobile learning trail: the missing dimension of the physical affordances," IEEE Transactions on Learning Technologies, vol. 8, no. 1, pp. 98-110, 2015.

[21] H. Crompton, D. Burke, K. H. Gregory, and C. Gräbe, "The use of mobile learning in science: a systematic review," Journal of Science Education and Technology, vol. 25, no. 2, pp. 149160, 2016.

[22] L. Mbati, "Mobile learning: moving past the myths and embracing the opportunities," International Review of Research in Open \& Distributed Learning, vol. 16, no. 2, pp. 115-135, 2015.

[23] C. C. Kao, P. S. Chiu, T. S. Chen, and T.-W. Hou, "AHP-based evaluation model for context-aware mobile learning system," Journal of Internet Technology, vol. 16, no. 2, pp. 267-275, 2015.

[24] A. I. Khan, H. Al-Shihi, Z. A. Al-Khanjari, and M. Sarrab, "Mobile learning (M-Learning) adoption in the Middle East: lessons learned from the educationally advanced countries," Telematics and Informatics, vol. 32, no. 4, pp. 909-920, 2015.

[25] C. Mouza and T. Barrett-Greenly, "Bridging the app gap: an examination of a professional development initiative on mobile learning in urban schools," Computers \& Education, vol. 88, pp. 1-14, 2015. 